\title{
The hidden benefits of writing retreats: Academic development and social interaction for nurses
}

\author{
Vicki Catherine Cope , Deborah Sundin, Aisling Smyth, Carol Wang, Gwendolyn Baum, Beverly Ewens, Fiona Foxall \\ School of Nursing and Midwifery, Edith Cowan University, Joondalup, Western Australia
}

Received: March 14, 2016

Accepted: June 12, 2016

Online Published: June 29, 2016

DOI: $10.5430 /$ jnep.v6n11p73

URL: http://dx.doi.org/10.5430/jnep.v6n11p73

\begin{abstract}
Not only do nurse academics teach, research, supervise, engage in professional development and professional organisations, they are compelled as academic nurse educators to write for publication, a task that involves expertise, creativity, skill and large amounts of time. This article describes a qualitative reflective analysis of the themes which surfaced during an offsite writing retreat attended by nurse faculty. The authors of this paper discovered an added invaluable benefit of their time at writing retreat: time to engage in social interactions that benefit their professional and personal development. In addition through experience of the retreat has been the increase in publications through the commitment to output, and academic development through engagement in mentoring, collegial partnerships, informal learning, and reflection.
\end{abstract}

Key Words: Social interaction, Academic development, Nursing knowledge, Writing for publication, Writing retreats

\section{INTRODUCTION}

Academics, regardless of professional association are admonished to "publish or perish", an imperative driven by the need to maintain and enhance individual and university profiles. The academics' efforts to meet this challenge are hampered by time and workload constraints, differing skills sets or even absence of the support and inspiration to begin. Writing retreats have been demonstrated as a successful strategy to address academics' challenges to juggle this mandate with the demands of their multi-tasked workloads. A qualitative reflective approach has been used to gather, discuss and share our experiences.

\subsection{Background}

"Publish or perish" or the current "be discoverable or die" remains the mantra by which individual academics and institutions are judged, a key indicator of research performance and thus of the relevant university's "success". ${ }^{[1]}$ Yet most academics remain under pressure to complete their responsibilities in a timely manner as they "struggle to juggle" their allocated teaching workload, community engagement, university service and research involvement, supervision and expected publication output. Productive writers often are at the upper echelons of academia. They have access to research assistants and are able to add their name to research projects, research grants and students' work ensuring the constant "many published by the few". ${ }^{[1]}$ This lack of inclusivity often relegates the career prospects of novice academics with the associated low research output and publications rates, having a direct effect on promotion prospects. Research and publication output, once the domain of a select few, are now expected for all academics. ${ }^{[2]}$ According to Lee and Boud ${ }^{[3]}$ "of the recent changes in higher education, it is arguably the expectation for all academics to undertake research that has

\footnotetext{
* Correspondence: Vicki Catherine Cope, PhD, RN, RM; Email: v.cope@ecu.edu.au; Address: School of Nursing and Midwifery, Edith Cowan University, Joondalup, Western Australia.
} 
generated the greatest threat, as well as some of the greatest opportunities for change". Subsequently, not only are teaching academics expected to produce teaching materials, develop courses, modules, curricula, policy documents, vast accreditation submissions, teach both online and external, as well as produce and deliver internal and face-to-face content, meet the high regulatory standards set by the professional bodies in addition to those set by the University, prepare students to succeed in writing a difficult external entrance to the profession exams, attend several meetings per week as well as sit on numerous committees, engage in professional development and be involved in professional committees external to the University, they are also expected to write research grant proposals to seek research monies, tender documents, journal articles, book chapters and books, as well as completing their own Masters or $\mathrm{PhD}$ should they also be studying. This is all extremely challenging not only as a novice academic, but when nurse faculty apply for tenure and promotion and must demonstrate that they reach or have the ability to reach the same level of research, academic writing and publication achievements as other faculty members who do not teach within professional programs.

Nurse academics have often been "head-hunted" to academia after expert clinical and/or practical nursing experience but more often than not are without background in teaching or writing. Upon arrival in the new setting, fledgling academics are expected to articulate their knowledge of specialty, educate within specialty and publish within their area of expertise or relating to nursing practice and/or teaching pedagogy. Lack of preparation in these areas, whilst striving to achieve their workload imperatives, can make any academic feel overwhelmed. Writing retreats provide a solution with an opportunity for academic staff to increase research output and publication rates. Writing retreats allow protected time to change pace and find space to think, plan, write and dedicate themselves to productive outcomes which ultimately increases research output. ${ }^{[4-7]}$ The authors of this paper discovered an added invaluable benefit of their time at this writing retreat: time to engage in social interactions that benefit their professional and personal development.

\subsubsection{The learning process on writing retreats}

The learning process has been dissected by a number of researchers and theorists. One of the most influential theories on learning and development is Bandura's Social Learning Theory. ${ }^{[8]}$ The theory describes learning as part of the cognitive process and can be conscious through direct instruction ("formal") or within a social context with observation from social interaction ("informal"). ${ }^{[8]}$ Thus the academic educator's learning can be supported both formally and informally. Formal learning includes attendance at training programmes, seminars and workshops. Informal learning is an unconscious or incidental process through social interaction, sharing and reflection ${ }^{[9]}$ and is observed in informal social settings. Offsite writing retreats create both a semistructured and a social environment for educators to focus on their publications ${ }^{[10]}$ and the offsite environment contributes to the educator's informal learning processes.

\subsubsection{Informal learning and mentoring on writing retreats}

Writing retreats have been discussed in the literature as being beneficial for increasing publication productivity for research centres at universities. Additionally, the writing retreat can be of great value to develop the individual's writing process and knowledge, and to contribute to the development of professional collegial relationships. ${ }^{[10]}$ Support and guidance provided by senior staff within writing groups or at writing retreats promotes and creates informal mentoring opportunities $^{[11-15]}$ thus contributing to the academic's informal learning process. Mentoring can lessen the individual's anxieties about writing and assist in improving their confidence level. Several mentoring partnerships may occur during the retreat allowing for networking and informal learning experiences between both partners. ${ }^{[10]}$ Ness, Duffy, McCallum, Price $^{[16]}$ realised their writing group was more beneficial than they originally anticipated, in that the setting created new skills for individuals by learning from each other and a very supportive environment developed.

\subsubsection{Discussion and reflection about writing}

A writing retreat brings together a cohort of academic writers with varying levels of writing skills and knowledge. Facilitating on-going discussions about writing during writing breaks allows for the novice writer (and experienced writer) to obtain immediate feedback and yields important opportunities of peer coaching and informal learning. ${ }^{[17]}$ Discussions contribute to promoting critical thinking, a focus on individual goals and reflection about one's own experience. A collective exploration of individual reflection adds richness to evaluation of writing and benefits professional development. ${ }^{[18]}$

\subsubsection{Time rich for writing and informal learning}

Many academic writers struggle to find time to write for publication due to professional and personal demands. ${ }^{[19]}$ Offsite writing retreats provide an environment solely for the purpose of writing. Escaping to a sequestered location without life-demands allows for blocks of writing time, and interaction and support from other writers, therefore, contributing to the informal learning process. Investment in supporting faculty members in their efforts of research, scholarship and academic writing can influence and increase levels of writing skill, competence and confidence. Moore ${ }^{[5]}$ claimed that given these challenges and requirements, universities must 
play a vital role in supporting staff in the areas of academic writing and publication. Participants from a writing retreat in Queensland noted that "by taking time out to write, rather than squeezing it around all the other work and activity associated with higher education, writing became an important academic pursuit, worth investing in". [20]

\subsubsection{Collegiality on writing retreats}

Writing retreats provide the opportunity for the attendees to be supported by their colleagues and mentors. ${ }^{[10]}$ A group of writers gathered in one setting allows for different perspectives about writing and individual skills to be discovered and shared. Close, on-going relationships are formed that may not have happened in the educators' daily lives at the university. Maher, Fallucca, Halasz ${ }^{[21]}$ found in their writing group that being together created a community of support and the attendees continually noted value in the contribution of others present. Collaboration and connections are developed into a synergistic effect that is beneficial for individual and group enthusiasm. Facilitating the development of collegiality and purposeful relationships among faculty with different levels of writing experience further promotes a positive research culture. ${ }^{[10]}$

Writing groups and writing retreats are the most common method of developing this collegial strength. ${ }^{[1]}$ They usually consist of a group of writers who want to work on their writing in the environment of a supportive writing group. The structure of the group can vary from being highly structured with allocated times for feedback, to less structured retreats where individuals gather together and provide more informal feedback during writing periods.

\subsection{The aims of the retreat}

The retreat aimed to increase publication output within the academic organization and uncovered additional and hidden benefits which include social interaction, peer support, and collegiality all contributing to academic development. This paper aims to add new aspects to existing literature by describing the hidden benefits experienced.

\subsection{The method guiding the paper}

A systematic method was used to guide the development of the material and research discussed in this paper. The authors all felt they had profited personally, professionally and productively from the retreat experience. A decision was therefore made to gather everyone's reflections, analyse these for themes and compare the emergent themes to the literature - a qualitative reflective approach.

Published by Sciedu Press

\section{METHODS}

Seven academics aged between 27 and 56 years from a School of Nursing \& Midwifery submitted expressions of interest to the Head of School and were approved to attend a five-day fully-funded and supported residential writing retreat which was held in a bush setting in Australia. Chalet accommodation was shared by pairs of academics in a beautiful, idyllic forest just over one hour away from the Central Business District. The chalets were pet-friendly which allowed academics to bring seven beloved dogs on retreat. The serenity of the writing space was only interrupted by the chorus of native Australian birds.

The aim of the retreat was to assist academics to meet their quota of research outputs by publication or to move forward the writing of their own $\mathrm{PhD}$. The retreat was scheduled prior to the commencement of the teaching semester which added focus to "getting something done" before the "real work of teaching" took precedence. Each academic prepared their own plan for what they wished to achieve within the retreat, many selecting a discrete piece of work to complete or work upon. The plan was submitted to the Head of School during the selection process.

The retreat was facilitated by a member of the academic staff who was participating in writing during the retreat. Because we had organized the retreat ourselves, we decided to write reflections on it. We applied for and received Ethics approval from the University Human Research Ethics Committee.

The range of the academics' nursing experience varied between 6 years to 35 years, with a cumulative total of 189 years of nursing. Juxtaposed to this was time in academia which ranged from just 6 weeks to 24 years, with two academics in the group at post - doctoral level.

The formal reflections included evolved from the informal evening discussions that enabled us to reflect on whether we had achieved the objectives we had set for the day's writing. These discussions followed a shared meal in a cottage and were usually sixty to ninety minutes duration. All participants were keen to share their experiences of their writing day overall, what had gone well and why and how they would build on these strategies to sustain their productivity for the remainder of the retreat and beyond. The facilitator encouraged all participants to share their daily experiences by giving everyone an opportunity to do so. This willingness to share experiences of a retreat evolved into a collective desire to formally disseminate our findings and perceived benefits of retreats with our colleagues through publication.

Following the retreat all participants were invited to provide a written reflection, in the format of their choosing for analy- 
sis as the foundation of the proposed publication. A thematic analysis was undertaken of the reflections from the seven participants and four themes consequently emerged. To ensure trustworthiness, member checking was conducted with all participants to ensure descriptions and categories were accepted by all participants. The offsite writing retreat was well received by all of the participants and increased their inspiration, confidence, and scholarly output during the protected time and through direct mentorship in a peaceful and conducive environment. Other benefits highlighted by the participants were the informal learning that arose from this rare opportunity for social networking. Participants' feedback indicated that the offsite writing retreat is a practical and sustainable strategy for increasing scholarly output through their reports and reflections of their experience of the writing retreat.

\section{Discussion}

The structure of the retreat was somewhat contrary to the recommendation of Murray and Newton ${ }^{[22]}$ of a highly structured format with the use of a facilitator whose role should be to lead and manage the group meetings and writing sessions. Although the most senior academic facilitated discussions, it was very informal and the participants required little facilitation during writing time, which is borne out by the outputs during the retreat (see Table 1). So, where there are autonomous, professional and motivated academics, who have been through an application and selection process with measureable objectives, facilitation can be informal and "from a distance". This is a new insight into the retreat process as the literature alludes to structured retreats being most effective in developing academic writing. ${ }^{[22]}$

Table 1. Publication Outputs

\begin{tabular}{lllll}
\hline Name* & $\begin{array}{l}\text { PhD } \\
\text { Proposal }\end{array}$ & $\begin{array}{l}\text { PhD } \\
\text { Chapter }\end{array}$ & $\begin{array}{l}\text { Journal Article } \\
\text { (Draft) }\end{array}$ & $\begin{array}{l}\text { Grant } \\
\text { Document }\end{array}$ \\
\hline $\begin{array}{l}\text { Chenfung } \\
\text { Grace }\end{array}$ & & 1 & 1 & \\
$\begin{array}{l}\text { Dolly } \\
\text { Mary }\end{array}$ & 1 & & & \\
Jacq & 1 & 2 & & 1 \\
Jill & & & & \\
Portia & & & 4 & 1 \\
Total & 2 & 3 & 5 & \\
\hline
\end{tabular}

*Participant's Pseudonyms

As a result of this retreat there have been four papers published in peer reviewed journals, completion of two $\mathrm{PhD}$ chapters and significant progress towards a PhD proposal.

All the authors who attended the retreat reported positive experiences. Reflective comments and feedback were collected by the informal facilitator and analysed for emerging themes.
Four recurrent themes emerged from their reflections. These were the offsite environment, being time rich, the blossoming of collegiality, and the commitment to output. Each will be discussed in turn.

\subsection{The offsite environment}

All participants found the venue conducive to writing. The location greatly contributed to the productivity and creativity of the attendees. Being near nature and writing rooms with windows were of benefit to providing a keen focus on writing. Distractions were minimal in this setting. A place of seclusion and tranquillity is revealed in these reflective comments:

"When we arrived at ..., I was astonished with the tranquillity, the peace, the green, the remembrance of the bush fire, the newborns, and the utterly hidden world in the wood! That was beautiful, that was a different world without much travelling, I thought".

"Surrounded by tranquillity, connected to nature, immersed in peace, being human, being quiet, being slow, being calm, being alone, being reflective, being myself, revisited my childhood, see my free spirit, these turned my mind away from daily routine, I feel that I can hear and feel more clearly".

\subsection{Being time rich}

Each day, the writing retreat participants followed the cycle of work, rest, and play, and as a result, not only was there a high writing output, collegiality and camaraderie increased and a feeling of contentment pervaded. Instead of the usual high stress levels surrounding the writing process, there was a distinct lack of stress and exhaustion, rather, there was serenity dispersed with fun. Various methods of supporting academic writing have been identified and studied in the literature. Numerous "how to" guides ${ }^{[23]}$ concerning writing for various purposes, including publication are available. However, many researchers agree that supporting academics in writing goes beyond the instructional to include interventions that take into account the individual and institutional settings, possibilities and challenges, to actual monetary and time support for writing. ${ }^{[24]}$ Providing dedicated time is one such strategy to improve and increase writing outputs, as demonstrated in the reflective comments below:

"The gift of being able to have dedicated time to focus on this writing has been fabulous, invaluable. On top of this, spending time in a serene setting totally separated from the clutter and minutiae of work and the 21 st century has allowed me to clear my head and truly focus on the paper, the writing". 
"There are few perks in academia but the chance to put life on hold for six nights, to spend five full days writing on a fully paid, writing retreat in a tranquil and beautiful setting is too good an opportunity to miss. Otherwise, my $\mathrm{PhD}$ will be written in snatched hours between work and home-life. Would I ever get it finished? I have been on three writing retreats and each has been good but the last one was by far the best and was the retreat in which I was working on my PhD".

It is interesting that this participant views attendance at a writing retreat as a "perk" when there is a clear expectation for all academics to publish. Perhaps a cultural change is necessary for writing retreats to become a recurring part of academic life and seen as necessary, rather than isolated activities for a lucky few.

"Nursing is wonderful. I absolutely love it and I love to show and share with newbies the hows and whys of care so educating is not the issue, but finding the time to write about what I do, the how's, the whys, and the ponderings on the wherefores often escapes me. This disjoint is jarring to a person who loves to write. So, imagine the joy that subsidised time away to write gives me. I nearly burst out of my skin to get to a writers retreat. I can abandon my first-world woes and immerse myself into my own little world that email forgot".

\subsection{The blossoming of collegiality}

The members of this writing group were all struck by the ease with which a sense of mutual support and teamwork developed and how this enhanced everyone's experience. Novice and experienced writers all benefited from the sharing, learning and mutual support. Lee, Boud ${ }^{[3]}$ suggest that the potential of writing groups is beneficial and advise that it is important to tailor the group structures and operations to the unique local environment; ... "there is no particular 'right' way or style needed for successful functioning". This was the case for our experience during our writing retreat and we would recommend giving thoughtful consideration to the planning of the retreat, surrounding structure and supportive interventions. In the beginning, we were contemplating the use of a structured facilitator with formal group discussions but we discovered that some of the formal practices did not suit this group who were already known to each other. We were surprised and pleased to realise the comfort and support of writing alongside each other and knowing that we were all experiencing similar challenges and barriers in writing. The structure during the retreat was informal; however advanced preparation was required by the facilitator and the attendees that led to trust and commitment in the process demonstrated by the immense support and the formation of collegial relationships. This is described in the following reflective comments:

"An unexpected benefit has been the bonds I have quickly forged with the friends I have shared this week with. Some I knew well and some I barely knew despite working with them each day at the Uni. We have had fun and, shared skills and helped each other with blocks and reflection throughout the week. This has really added to and possibly been the best part of the week".

"It was a fantastic way to bond with colleagues, to gain different perspectives and to troubleshoot writing and research issues. Each evening we would meet and discuss our progress and future plans. Discussions on a variety of research related topics were casual and free flowing, meaning we all felt at ease in asking questions and participating. The wide range in research interests, academic experience and writing expertise was actually hugely helpful as it was reflected in diverse input and points of view".

Supportive, collegial relationships spring from and can be reinforced through peer support and peer feedback sessions. Similarly to Jackson ${ }^{[10]}$ the collegial relationships we enjoyed were a central element of the retreat and were essential to creating the "community of scholars" milieu upon which the retreat was based.

Engagement in peer support and feedback is one of the many aspects of being a member of the academic community. In this capacity, the academic's expertise and contribution is or should be acknowledged and recognised. Reaching or achieving the realisation that one has something to add to the academic discourse is an important step along the academic's pathway as they move from one identity to another (albeit with changing and increasing responsibilities). As Jawitz claims, "[i]dentity is built around social engagement and is constantly being renegotiated as individuals move through different forms of participation". ${ }^{[25]}$ We have observed that newer writers and/or researchers felt empowered when they recognized that they have something to offer when advising or providing feedback to others.

\subsection{The commitment to output}

The aim of writing retreat is increased publication output but on-going commitment to this aim is just as, if not more important. Positive experiences and emotions can be intrinsically motivating. ${ }^{[26]}$ The reflections of these authors indicated that a positive retreat experience can be empowering:

"New time, new space, new perspective, new experience, new ideas, new stories, thanks writing retreat! The team was great, there are many writing experts in the team 
which I soon realised was very beneficial: with the experts around me, I have received much attention with what I do in my research area, I could ask questions, getting ideas and support. By getting to know them better on the personal level and professional level, I feel much more comfortable to talk about my project, having discussion, add new ideas and insights."

"Being offered the opportunity to go on a retreat made me feel valued as an employee and a researcher. The week away from the world enabled me to make significant progress in the writing of my $\mathrm{PhD}$. Just as importantly, it was the perfect environment to spark conversations about possible collaborations and projects for the future. It was a win- win situation and I couldn't recommend it strongly enough".

These retreats often provide surges of writing motivation and output. Sadly, this is often subsumed by an increased workload once participants return to work. The bonds that formed during retreat may continue and strengthen, or indeed disintegrate in the face of these challenges. ${ }^{[14]}$

At the close of retreat, commitments about practice and prioritisation are usually made. By their very nature, writing retreats are a collective of individuals with shared writing and, or research interests. Collaboration and networking following a retreat is likely to simulate the momentum initiated at the retreat. The opportunity to collaborate into the future may occur naturally, as it did for our group but some stimulus or opportunity might need to be provided, such as writing groups (either within a faculty or within the e-community). Writing should be about reflection and analysis of the area between teaching and research ${ }^{[27]}$ and perhaps departments or institutions may wish to explore organised ways of capitalising on this momentum.

\section{IMPLICATIONS FOR ACADEMIC DEVELOP- ERS AND THE FUTURE}

Further research is required in order to elicit wider views of this activity; if the informal learning that took place on the retreat has a significant impact on future writing and scholarly output and indeed, if that informal learning is inferior or superior to the formal learning activities that take place on a highly structured and facilitated retreat. The participants on this writing retreat would argue that the informal learning was individualised, as specific issues, highlighted by individual participants were addressed at an appropriate time and that indeed, a number of "light bulb" moments were encountered, leading to deep learning. There is no doubt that the scholarly output from this particular writing retreat was significant but sadly, that does not alter the fact that such an event may be viewed as an expensive extravagance because of the accommodation costs and therefore, no further retreats are anticipated in the foreseeable future. A compromise has been made, in that academic staff will be given time out from work during the semester break, as long as individual participants meet the costs. This may be a good compromise if individuals are motivated and have specific objectives because time to write is often the hardest commodity to negotiate and procrastination can be difficult to overcome without protected time. It may be useful to determine the views of academic staff on this point.

Given the fiscal constraints of Faculty and personal financial constraints, it may be envisioned that writing retreats takes place on campus with no personal costs and only "in-kind" costs to the School for allowing writing time. Encouraging scholarly activity amongst academics could foster partnerships amongst academics (this paper is testimony to that), students, clinical staff and industry partners, so increasing community engagement. If academic leaders, who are driving the agenda for research and scholarly activity, wish to see relatively quick but lasting results, surely such activities should become the norm within the academic calendar and should be sustained.

\section{Limitations}

The convenience sample was relatively small and as a result, the findings may limit generalisability. Additionally, the participants' reflections may not be a complete reflection of the situations described.

\section{CONFlicts OF INTEREST Disclosure}

The authors declare that they have no conflicts of interest.

\section{REFERENCES}

[1] McGrail M, Rickard C, Jones C. Publish or perish: a systematic review of interventions to increase academic publication rates. Higher Education Research \& Development. 2006; 25(1): 19-35. http://dx.doi.org/10.1080/07294360500453053

[2] Casey B, Barron C, Gordon E. Reflections on an in-house academic writing retreat. Aishe-j: The All Ireland Journal of Teaching and Learning in Higher Education. 2013; 5(1): 1041-10414.

[3] Lee A, Boud D. Writing Groups, Change and Academic Identity: Research development as local practice. Studies in Higher Education. 2003; 28(2): 187-200.

[4] Gilligan L, Cretchley P, George L, et al. Evolution and emerging 
trends of university writing groups. Queensland Journal of Educational Research. 2003; 19(1): 28-41.

[5] Moore S. Writers' retreats for academics: exploring and increasing the motivation to write. Journal of Further and Higher Education. 2003; 27(3): 333-343. http://dx.doi.org/10.1080/0309877 032000098734

[6] Murray R. Writing development for lecturers moving from further to higher education: a case study. Journal of Further and Higher Education. 2002; 26(3): 229-239. http://dx.doi .org/10. 1080 103098770220149585

[7] Grant B. Writing in the company of other women: Exceeding the boundaries. Studies in Higher Education. 2006; 31(4): 483-495. http://dx.doi.org/10.1080/03075070600800624

[8] Bandura A. Social learning theory. Englewood Cliffs, NJ: Prentice Hall; 1977.

[9] Marsick VJ, Watkins KE. Informal and Incidental Learning. New Directions for Adult and Continuing Education. 2001; 2001(89): 25-34. http://dx.doi.org/10.1002/ace.5

[10] Jackson D. Mentored residential writing retreats: a leadership strategy to develop skills and generate outcomes in writing for publication. Nurse Education Today. 2009; 29(1): 9-15. PMid:18692282. http://dx.doi.org/10.1016/j.nedt.2008.05.018

[11] Cable CT, Boyer D, Colbert CY, et al. The writing retreat: a highyield clinical faculty development opportunity in academic writing. Journal of Graduate Medical Education. Jun 2013; 5(2): 299-302. PMid:24404277. http://dx.doi.org/10.4300/JGME-D-12-0 0159.1

[12] Horstman P, Theeke L. Using a professional writing retreat to enhance professional publications, presentations, and research development with staff nurses. Journal for Nurses in Staff Development. 2012; 28(2): 66-68. PMid:22449879. http://dx.doi.org/10.1097/N ND. 0b013e31824b417a

[13] Keen A. Writing for publication: pressures, barriers and support strategies. Nurse Education Today. 2007; 27(5): 382-388. PMid:16904796. http://dx.doi.org/10.1016/j.nedt. 2006 .05 .019

[14] Petrova P, Coughlin A. Using structured writing retreats to support novice researchers. International Journal for Researcher Development. 2012; 3(1): 79-88. http://dx.doi.org/10.1108/17597 511211278661

[15] Stone T, Levett-Jones T, Harris M, et al. The genesis of 'the Neophytes': a writing support group for clinical nurses. Nurse Education Today. 2010; 30(7): 657-661. PMid:20096487. http://dx.doi.o $\mathrm{rg} / 10.1016 / \mathrm{j}$. nedt $.2009 \cdot 12.020$
[16] Ness V, Duffy K, McCallum J, et al. Getting published: Reflections of a collaborative writing group. Nurse Education Today. 2014; 34(1): 1-5. PMid:23623744. http://dx.doi.org/10.1016/j.n edt. 2013.03.019

[17] Peinhardt RD, Hagler D. Peer Coaching to Support Writing Development. Journal of Nursing Education. 2013; 52(1): 24-28. PMid:23181459.

[18] Bosanquet A, Cahir J, Jacenyik-Trawoger C, et al. From speed dating to intimacy: methodological change in the evaluation of a writing group. Higher Education Research \& Development. 2014; 33(4): 635648. http://dx.doi.org/10.1080/07294360.2013.863845

[19] Swaggerty EA, Atkinson TS, Faulconer JL, et al. Academic Writing Retreat: A Time for Rejuvenated and Focused Writing. The Journal of Faculty Development. 2011; 25(1): 5-11.

[20] Myatt P, Gannaway D, Green W. Views from a writing retreat. Higher Education Research \& Development Society of Australiasia Inc. 2013; 35(3): 1-4.

[21] Maher M, Fallucca A, Halasz HM. Write on! Through to the Ph.D.: using writing groups to facilitate doctoral degree progress. Studies to Continuing Education. 2013; 35(2): 193-208. http: //dx.doi.org/10.1080/0158037X.2012.736381

[22] Murray R, Newton M. Writing retreat as structured intervention: margin or mainstream? Higher Education Research \& Development. 2009; 28(5): 541-553. http://dx.doi.org/10.1080/0729436 0903154126

[23] Heyman B, Cronin P. Writing for publication: adapting academic work into articles. British Journal of Nursing. 2005; 14(7): 400403. PMid:15924017. http://dx.doi.org/10.12968/bjon.2 005.14 .7 .17947

[24] Gopee N, Deane M. Strategies for successful academic writing Institutional and non-institutional support for students. Nurse Education Today. 2013; 33(12): 1624-1631. PMid:23473750. http: //dx.doi.org/10.1016/j.nedt.2013.02.004

[25] Jawitz J. Academic identities and communities of practice in a professional discipline. Teaching in Higher Education. 2009; 14(3): 241-251. http://dx.doi.org/10.1080/13562510902898817

[26] McAlpine L, Amundsen C, Jazvac-Martek M. Living and imagining academic identities: Perceptions of doctoral students and pre-tenure academics. In: Akerlind LMG, ed. Visions of academic practice?: The public and personal faces of becoming an academic in the social sciences. London: Palgrave Macmillan; 2010: 125-154.

[27] Gibbs A. What would a scholarship of publication look like? Higher Education Research \& Development. 2013; 32(4): 687-689. http: //dx.doi.org/10.1080/07294360.2013.803310 